\title{
OCCUPATIONAL EXPOSURE TO 50 HZ MAGNETIC FIELDS DOES NOT ALTER RESPONSES OF INFLAMMATORY GENES AND ACTIVATION OF SPLENIC LYMPHOCYTES IN MICE
}

\author{
XUE LUO ${ }^{1}$, SHUJIE JIA ${ }^{2}$, RENYAN LI ${ }^{3}$, PENG GAO ${ }^{4}$, and YANWEN ZHANG ${ }^{4}$ \\ ${ }^{1}$ Third Military Medical University, Chongqing, China \\ Institute of Tropical Medicine \\ ${ }^{2}$ Eighth Hospital of Xi'an, Shaanxi, China \\ Department of Pharmacy \\ ${ }^{3}$ Key Laboratory of Birth Defects and Reproductive Health, Chongqing, China \\ Chongqing Institute of Population and Family Planning \\ ${ }^{4}$ Third Military Medical University, Chongqing, China \\ Department of Occupational Health
}

\begin{abstract}
Objectives: The objective of the present study was to observe the effects of $50 \mathrm{~Hz}$ magnetic fields (MFs) on the immune function of splenic lymphocytes in mice. Material and Methods: Twenty male Kunming mice (6 weeks old), weighing 18$25 \mathrm{~g}$, were randomly divided into sham exposure $(\mathrm{N}=10)$ and $500 \mu \mathrm{T}$ MFs $(\mathrm{N}=10)$ groups. The mice in the MFs group were exposed to $500 \mu \mathrm{T}$ MFs for $8 \mathrm{~h}$ daily ( 5 days/week) for up to 60 days. In vitro study was carried out to examine the effects of $50 \mathrm{~Hz}$ MFs on the expression of inflammatory factor genes and a cluster of differentiation 69 (CD69) in mouse prime splenic lymphocytes activated by para-Methoxyamphetamine (PMA) and ionomycin. In the in vitro experiments, lymphocytes were isolated from the spleen of 10 healthy Kunming mice, the cells were cultured in the Roswell Park Memorial Institute 1640 medium (RPMI-1640) and exposed to $0 \mu \mathrm{T}, 250 \mu \mathrm{T}, 500 \mu \mathrm{T}$, or $1 \mathrm{mT}$ MFs in an incubator under 5\% carbon dioxide $\left(\mathrm{CO}_{2}\right)$ at $37^{\circ} \mathrm{C}$ for $6 \mathrm{~h}$. The levels of interleukin-2 (IL-2), IL-4, interferon-gamma (IFN- $\gamma$ ), GATA binding protein 3 (GATA-3) and T cell-specific T-box transcription factor (T-bet) were assessed by the real-time quantitative reverse transcription polymerase chain reaction (RT-qPCR), respectively. The expression of CD69 was checked using the flow cytometry. Results: Under our experimental conditions, body weight of the mice exposed to occupational, extremely low frequency-electromagnetic fields (ELF-EMFs) significantly decreased on day 20 and day 30. There were no significant changes observed in vivo in spleen weight, splenic coefficient, splenic histology profile and cytokine production in spleen tissues. Our in vitro experiments showed that $50 \mathrm{~Hz}$ MFs had no effect on the expression of these genes and CD69 to primary splenic cells. Conclusions: In conclusion, under the applied experimental conditions, occupational exposure to $50 \mathrm{~Hz}$ magnetic field did not alter responses of inflammatory genes and activation of splenic lymphocytes in mice, except for body weight.
\end{abstract}

Key words:

Mice, Magnetic fields, Inflammation, Spleen, Lymphocytes, Cytokine

This work was supported by the grant No. 2012XJQ07 from the Third Military Medical University entitled "Mechanism research on CD4+ T cell activation inhibition caused by aluminum overload through comparative proteomics". Project manager: Xue Luo, Ph.D., M.D.

Received: November 24, 2014. Accepted: May 9, 2015.

Corresponding author: Y. Zhang, Third Military Medical University, Department of Occupational Health, 30 Gaotanyan Road, Shapingba District, Chongqing 400038, China (e-mail: zhangyw20022002@aliyun.com). 


\section{INTRODUCTION}

Electromagnetic equipment is widely used and we are increasingly exposed to extremely low frequency-electromagnetic fields (ELF-EMFs). However, knowledge on the effects of these ELF-EMFs on public health is insufficient. Scientific and public interest in possible health hazards due to exposure to electromagnetic fields have arisen, and the main concerns are focused on their carcinogenic potential [1-3]. Extremely low frequency-electromagnetic fields have significant effects, i.e., they cause oxidative deoxyribonucleic acid (DNA) damage [4], change reproductive characteristics such as sperm count and morphology [5], increase the amount of testosterone [6] and have effect on the central nervous system [7-10], and cardiovascular system [11].

Based on previous epidemiological studies, Schuz [12], using a pooled analysis, has demonstrated an approximately 2-fold increase in the risk of childhood cancer at ELF-MF exposures $\geq 0.4 \mu \mathrm{T}$. Additionally, the analysis has shown consistency between the studies across the countries, with different designs, different methods of exposure assessment and different systems of power transmission, and distribution. The judgement that ELF-MFs are possibly carcinogenic and may cause childhood leukemia remains valid. Wünsch-Filho [13] has evaluated the effect of $60 \mathrm{~Hz}$ magnetic fields (MFs) on acute lymphocytic leukemia (ALL) in the State of São Paulo, Brazil. This case-control study included all cases $(\mathrm{N}=162)$ recruited from 8 hospitals between January 2003 and February 2009. The children living within $200 \mathrm{~m}$ from power lines had an increased risk of ALL, compared to the children living within $600 \mathrm{~m}$ or more from the power lines. On the other hand, Kheifets [14] has reported that extensive epidemiological research conducted during the past 20 years on occupational EMF exposure did not indicate strong or consistent associations with cancer or any other health outcomes. Those epidemiological studies focused on the association between exposure to ELF-EMFs and the incidence of certain cancers.
As the immune system is involved in carcinogenesis, it is important to have a profound knowledge on the influence of ELF-EMFs exposure on it - several experimental studies have examined those epidemiological reports with conflicting findings.

Cossarizza et al. [15] have exposed human peripheral blood mononuclear cells to extremely low frequency pulsed electromagnetic fields (PEMFs). Pulsed electromagnetic fields increased both the spontaneous and the phytohaemagglutinin- (PHA), and tissue polypeptide antigen-induced (TPA) production of interleukin-1 (IL-1) and IL-6 [15]. Gobba et al. [16] have reported on natural killer (NK) cell activity in 52 workers exposed to different levels of ELF-MFs whilst performing various activities. Extremely low frequency-electromagnetic fields are considered to be possibly carcinogenic, as existing data show that they can reduce NK activity. The findings have also suggested that ELF-MFs affected the immune system response to bacterial challenges.

However, several scientists share the opposite opinion on the effects of EMFs. Ikeda [17] has observed the effects of exposure to $50 \mathrm{~Hz}$ and $60 \mathrm{~Hz}$ at $500 \mu \mathrm{T}$, $100 \mu \mathrm{T}, 20 \mu \mathrm{T}, 2 \mu \mathrm{T}$ ELF-MFs on the immunological function of human peripheral blood mononuclear cells (PBMCs) obtained from healthy male volunteers. Extremely low frequency-electromagnetic fields had no cytotoxic activities and did not affect cytokine production in human PBMCs. Kleijn [18] has used PBMCs isolated from the blood of healthy volunteers, which were stimulated with specific Toll-like receptors 2 (TLR2) and TLR4 ligands, and with several microorganisms. The cells were subsequently exposed to $3 \mu \mathrm{T}$ for $30 \mathrm{~min}$, and it has been found that ELF-MFs did not modulate the innate immune response in human primary cells after TLR stimulation in vitro. Bouwens [19] has determined the kinetics of cytokine and other inflammation-related genes in a human monocytic leukemia cell line, human acute monocytic leukemia (THP-1), and in primary monocytes and macrophages 
exposed to $5 \mu \mathrm{T}$ at $50 \mathrm{~Hz}$ MFs for $30 \mathrm{~min}$. Under those exposure conditions, MFs did not alter responses of inflammatory genes and proteins in human monocytes and immune cell lines.

Considering vital biological roles of splenic lymphocytes in the immune function, we were interested whether exposure to $50 \mathrm{~Hz}$ MFs can lead to changes in the immune function estimated using in vivo and in vitro experiments. In the present study, we determined the effects of $500 \mu \mathrm{T}$ at $50 \mathrm{~Hz}$ MFs (subchronic occupational exposure) in Kunming mice, which included body weight, splenic weight, splenic coefficient and cytokine production in the spleen. Moreover, in our in vitro study we examined the effects of $50 \mathrm{~Hz}$ MFs on the expression of inflammatory factor genes and a cluster of differentiation 69 (CD69) in mouse prime splenic lymphocytes activated by phorbol ester para-Methoxyamphetamine (PMA) and ionomycin.

\section{MATERIAL AND METHODS}

\section{Experimental protocol}

In vivo: 20 Kunming mice (6 weeks old), weighing $18-25 \mathrm{~g}$, were randomly divided into the sham exposure $(\mathrm{N}=10)$ and $500 \mu \mathrm{T}$ MFs $(\mathrm{N}=10)$ groups. The mice in the MFs group were exposed to $500 \mu \mathrm{T}$ MFs for $8 \mathrm{~h}$ daily (5 days/ week) for up to 60 days. Body weight, spleen weight, splenic coefficient, splenic histology profile and cytokine production in spleen tissues were observed in vivo.

In vitro: Our study was carried out to examine the effects of $50 \mathrm{~Hz}$ MFs on the expression of inflammatory factor genes and CD69 in mouse prime splenic lymphocytes activated by PMA and ionomycin. Lymphocytes were isolated from the spleen of 10 healthy Kunming mice, the cells were cultured in the Roswell Park Memorial Institute 1640 medium (RPMI-1640) and then, exposed to $0 \mu \mathrm{T}, 250 \mu \mathrm{T}$, $500 \mu \mathrm{T}, 1 \mathrm{mT}$ MFs in an incubator under $5 \%$ carbon dioxide $\left(\mathrm{CO}_{2}\right)$ at $37^{\circ} \mathrm{C}$ for $6 \mathrm{~h}$. The levels of IL-2, IL-4, interferon-gamma (IFN- $\gamma$ ), GATA binding protein 3 (GATA-3) and $\mathrm{T}$ cell-specific T-box transcription factor (T-bet) were

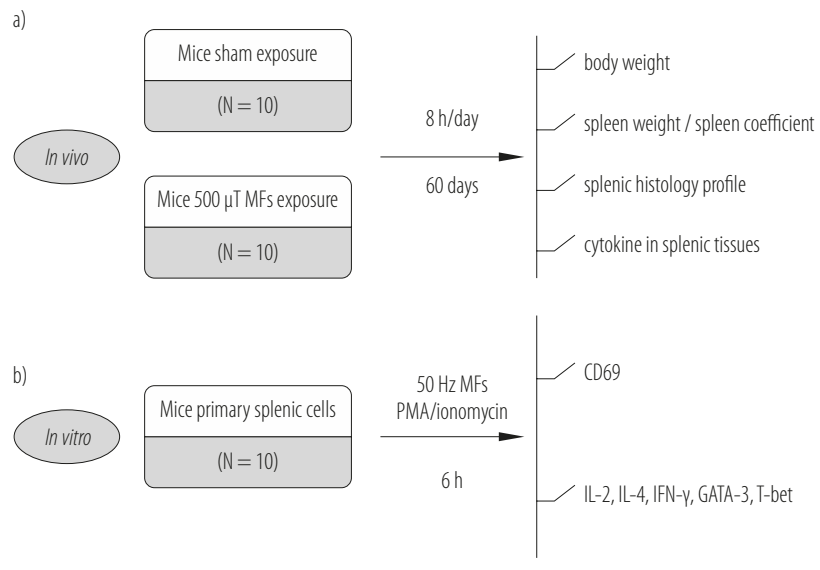

MFs - magnetic fields; PMA - para-Methoxyamphetamine; CD69 cluster of differentiation 69; IFN- $\gamma$ - interferon-gamma; T-bet - T cellspecific T-box transcription factor; IL - interleukin; GATA-3 - GATA binding protein 3 .

Fig. 1. Experimental protocol: a) solenoid, b) IT'IS Foundation exposure system (Zurich, Switzerland)

assessed by the use of the real-time quantitative polymerase chain reaction (RT-qPCR), respectively. The expression of CD69 was checked using flow cytometry.

The experimental protocol is illustrated in Figure 1.

\section{Animals}

The 30 male adult (6 weeks old, 18-25 g) Kunming mice were purchased from the Experimental Animal Center of the Third Military Medical University (Chongqing, China). All procedures were approved by the Chinese Ministry of Science and Technique for Accreditation of Laboratory Animal Care. Specific pathogen free mice were kept under steady state micro-environmental conditions, and were housed at $22 \pm 2{ }^{\circ} \mathrm{C}, 55 \pm 10 \%$ humidity and maintained on a 12-h light-dark cycle (lights on at 7 a.m.). The animals received standard laboratory food and water ad libitum.

Twenty Kunming mice were randomly divided into the sham exposure $(\mathrm{N}=10)$ and $500 \mu \mathrm{T}$ MFs $(\mathrm{N}=10)$ groups. The sham exposure is comparable to MFs group. It was called "cage controls," that is, mice in parallel kept 
in an animal room with "basal" exposure with additional stress like exposure group, but without MFs exposure.

The other 10 Kunming mice were used for in vitro experiments.

\section{Cell preparation and stimulation}

Kunming mouse spleen single-cell suspensions were prepared by grinding spleen tissue with glass slides and passing it through a nylon mesh. Red blood cells were removed with a Red Blood Cell Lysis Buffer (C3702, Beyotime Institute of Biotechnology, Jiangsu, China). Splenocytes (at $2 \times 10^{6}$ cells $/ \mathrm{ml}$ ) were stimulated with PMA $(50 \mathrm{ng} / \mathrm{ml})$ or ionomycin $(1 \mu \mathrm{M})$ in the absence or presence of MF exposure $(250 \mu \mathrm{T}, 500 \mu \mathrm{T}, 1 \mathrm{mT})$ in a $35 \times 10 \mathrm{~mm}$ cell culture dish. They were then incubated for $6 \mathrm{~h}$ or $24 \mathrm{~h}$ at $37^{\circ} \mathrm{C}$ in a $5 \% \mathrm{CO}_{2}$ atmosphere.

\section{Exposure system for in vivo (solenoid) [20]}

The $50 \mathrm{~Hz}$ (power frequency) MFs were generated in an energizing solenoid, obtained by a winding copper wire $(\varnothing=1 \mathrm{~mm})$ with an internal diameter (D) equal $35 \mathrm{~cm}$, length (L) $-90 \mathrm{~cm}$ constructed on a glass fiber cylinder (Figure 2).

The solenoid was powered by a waveform generator (33522A, Agilent Technologies Inc., Santa Clara, CA, USA) with preprogrammed signals. The strength and

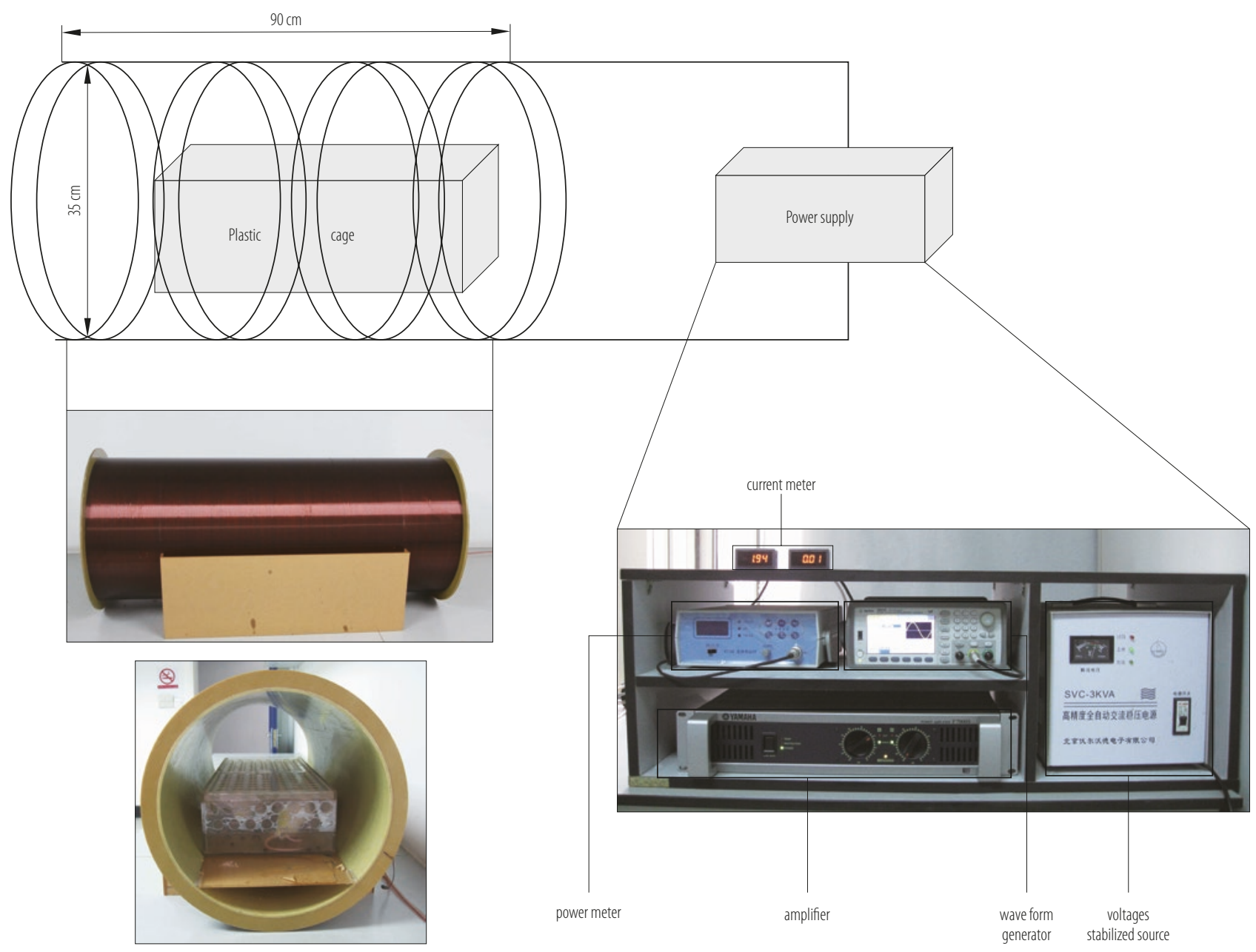

Fig. 2. Electromagnetic field generator design: animal exposure system and the power supply system 
frequency of the voltage signal were controlled by the generator, and a power amplifier (P7000s, Yamaha Corporation, Hamamatsu, Shizuoka, Japan) was used to amplify the voltage signal. Current in the solenoid was monitored by a current meter (IN5135-220, Shanghai Inlu Electronic Co., Ltd., Shanghai, China) connected in series with the solenoid. The intensity of the $50 \mathrm{~Hz}$ MFs in the exposure chambers was measured with PMM 8053B field meter with EHP-50C probe (Narda Safety Test Solutions, Segrate, Milano, Italy) weekly.

In the preliminary experiments, we found that there was an approximate proportional relationship between current I and magnetic field intensity $\mathrm{B}(\mathrm{B} \approx 0.275)$. The uniformity of the MFs in the exposure area was $\pm 3 \%$. In order to achieve thermal equilibrium, the exposure system was turned on at least $0.5 \mathrm{~h}$ before the experiments, which ensured a stable magnetic field intensity. During the animal exposure period, all the field measurements were performed by a person not involved in the study. In order to maximally eliminate heating in the solenoid during exposure, our animal exposure system was kept under steady state micro-environmental conditions, and the conditions were: temperature $-22 \pm 2^{\circ} \mathrm{C}, 55 \pm 10 \%$ - humidity.

\section{Exposure system for in vitro}

(IT'IS Foundation, Zurich, Switzerland) [21]

The ELF-EMFs exposure system was provided and built by the Foundation for Research on Information Technologies in Society (IT'IS Foundation, Zurich, Switzerland). In brief, the setup consisted of two 4-coil systems ( 2 coils with 56 windings, 2 coils with 50 windings), each placed inside a $\mu$-metal box (the $\mu$-metal is a special alloy for high magnetic shielding). Current in the bifilar coils could be switched to parallel for field exposure or non-parallel for sham control. Both systems were fitted inside a commercial incubator (Heracell 240i, Thermo Scientific, Langenselbold, Germany) to ensure constant environmental conditions $\left(37^{\circ} \mathrm{C}, 5 \% \mathrm{CO}_{2}, 95 \%\right.$ humidity). In addition, temperature was monitored with platinum (Pt100) probes at the location of the dishes and maintained at $36.5-37.5^{\circ} \mathrm{C}$ during exposure. The temperature difference between the chambers did not exceed $0.3^{\circ} \mathrm{C}$. Two fans per box were mounted to guarantee an adequate atmospheric exchange in the exposure chambers.

The setup was optimized for homogeneous field distribution, maximum field strength, minimum temperature increase and minimum vibrations. A current source was developed based on 4 audio amplifiers (Agilent Technologies, Zurich, Switzerland), which allowed MFs up to $3.5 \mathrm{mT}$. The field could be arbitrarily changed within the frequency range of $3-1250 \mathrm{~Hz}$ by a computer controlled by an arbitrary function generator. To enable blinded exposures, the computer randomly determined which coil was exposed and which coil was sham. The fields as well as all the sensors were continuously monitored. All the experiments were performed at a field frequency of $50 \mathrm{~Hz}$ sinusoidal at intermittent exposure. Dose-response effects were studied at 3 different magnetic flux densities of $250 \mu \mathrm{T}, 500 \mu \mathrm{T}$ and $1 \mathrm{mT}$ at a constant exposure time of $6 \mathrm{~h}$.

\section{Sample collection and processing}

After 60 days, the animals were sacrificed under ether anesthesia immediately after the end of exposure. The animals did not eat $8 \mathrm{~h}$ before the experiment but had free access to water ad libitum. Spleens were carefully dissected from each animal, blotted free of blood with saline, weighed, and stored at $-20^{\circ} \mathrm{C}$ for determination of cytokine production.

\section{Body weight and organ coefficient}

Body weight of Kunming mice was measured every week, and the weight growth curves of the mice during the experimental period were calculated. When the mice were sacrificed, the spleen from each mouse was weighed to calculate the organ coefficient (organ/body weight ratio):

organ coefficient $=$ organ weight $\times 100 /$ body weight 
Morphological and histological analyses

Excised spleens were fixed in $4 \%$ paraformaldehyde solution, dehydrated in serial alcohol solutions, embedded in paraffin, cut into 5- $\mu$ m-thick sections stained with hematoxylin-eosin (HE) and examined under a light microscope.

Real-time quantitative reverse transcription

polymerase chain reaction (RT-qPCR)

Complementary DNA was obtained from total ribonucleic acid (RNA) extracted from the mice spleen or from $1 \times 10^{6}$ prime splenic cells using TRIzol ${ }^{\circledast}$ reagent (Invitrogen, Carlsbad, USA), according to the manufacturer's instructions. Moloney murine leukemia virus (MMLV) reverse transcriptase (Promega, Madison, WI, USA) was used for complementary DNA (cDNA) synthesis. Primers used to amplify the gene fragments are available from the authors (Table 1).

Transcripts were quantified by the RT-qPCR on the BioRad CFX96 real-time PCR detection system (BioRad Laboratories, Hercules, CA, USA) with SYBR Green IQTM Supermix (Bio-Rad Laboratories, Hercules, CA, USA) according to the manufacturer's instructions. The comparative threshold cycle method and an internal control (glyceraldehyde-3-phosphate dehydrogenase - GAPDH) were used to normalize expression of the target genes.
Flow cytometry

Splenocytes $(1 \times$ BioRad CFX96 real-time PCR detection $10^{6}$ ) from Kunming mice were washed once with a FACS buffer (phosphate buffered saline - PBS, $\mathrm{pH}=7.2$, containing $0.9 \% \mathrm{NaN}_{3}$ and $0.4 \%$ bovine serum albumin) and stained with a fluorescein isothiocyanate- (FITC-) labeled anti-mouse CD69 monoclonal antibody (mAb) (BioLegend, Kithorn, the Netherlands) or the non-specific staining control mAb (BioLegend, Kithorn, the Netherlands), respectively. At least 10000 cells were assayed by the FASCalibur flow cytometer (Becton Dickinson, Mountain View, CA, USA).

\section{Ethical approval of the study protocol}

All procedures involving animal care and experimental procedures conformed to the guidelines on handling and training laboratory animals of both the National Institute of Health and the Third Military Medical University. The study protocol was approved by the Ethics Committee on the Use and Care of Animals, Third Military Medical University (Chongqing, China).

\section{Statistical analysis}

All experiment data in our experiment were expressed as mean \pm standard deviation $(\mathrm{M} \pm \mathrm{SD})$. Statistical analyses were performed using SPSS 13.0 package programmer (SPSS Inc., Chicago, IL, USA). Multifactor variance analysis (General Linear Model / Repeated Measures)

Table 1. Primer sequences for the real-time quantitative reverse transcription polymerase chain reaction (RT-qPCR)

\begin{tabular}{lll}
\hline \multirow{2}{*}{ Gene } & \multicolumn{1}{c}{ forward } & \multicolumn{1}{c}{ Primer sequence } \\
\cline { 2 - 3 }$I F N-\gamma$ & AGGCCATCAGCAACAACATAAGCG & GGCGCTGGACCTGTGGGTTG \\
T-bet & CGCGCGAGGACTACGCATTG & CGGCCACGGTGAAGGACAGGA \\
$I L-4$ & AGGAGCCATATCCACGGATGCGA & TGCGAAGCACCTTGGAAGCCC \\
GATA-3 & AAGGCAACCACGTCCCGTCC & TTTGCCGCCATCCAGCCAGG \\
$I L-2$ & ACAGGAACCTGAAACTCCCCAGGA & CCAGAACATGCCGCAGAGGTCC \\
GAPDH & CATGGCCTTCCGTGTTCCTA & CCTGCTTCACCACCTTCTTGA \\
\hline
\end{tabular}

GAPDH - glyceraldehyde-3-phosphate dehydrogenase. Other abbreviations as in Figure 1. 
and Independent-Samples t-Test were used to assess changes of body weight between the 2 groups. Independent-samples t-test was used to compare the effects of occupational ELF-EMFs exposure on the spleen coefficient, IFN- $\gamma$, T-bet, IL-4, GATA-3, and IL-2 with the control group. Statistical significance was assumed at $\mathrm{p}<0.05$.

\section{RESULTS}

\section{Changes in body weight and organ coefficients of mice}

The effects of occupational ELF-EMFs exposure on the mice's body weight are presented in Figure 3.

Body weight of each mouse increased gradually week by week, except for day 50 and day 60 . Body weight of the mice exposed to occupational ELF-EMFs was significantly decreased in day 20 and day 30 compared to that of the mice from the sham exposure group. Extremely low frequencyelectromagnetic fields could affect mice's body weight.

To determine the target organ following ELF-EMFs exposure, spleen weight and spleen coefficient were evaluated. Figure 4 shows that there were no significant differences between the exposed group and the sham exposure group. Occupational ELF-EMFs had no adverse effect on histology profile.

To investigate the role of occupational ELF-EMFs on splenic histology profile, we used Kunming mice as

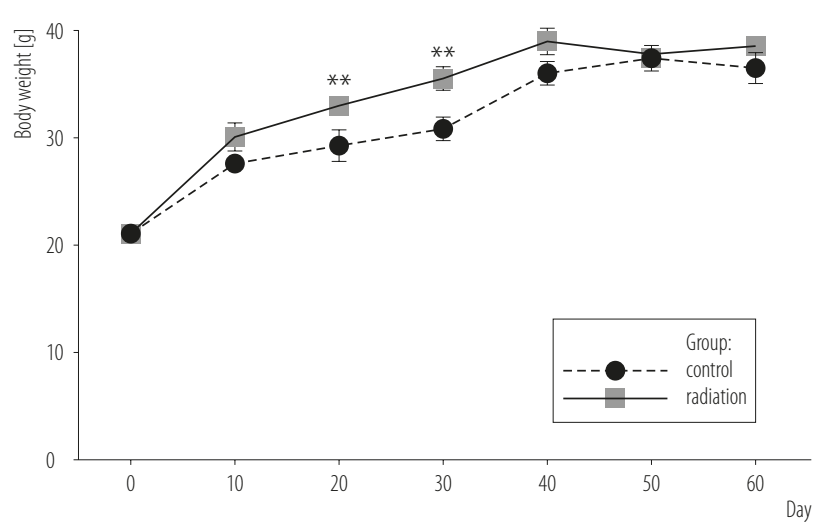

** Exposure to $50 \mathrm{~Hz}$ magnetic fields (MFs) significantly differed from the sham exposure, $\mathrm{p}<0.01$.

Fig. 3. Body weight of the mice exposed to $50 \mathrm{~Hz}$ magnetic fields (MFs) and of those from the control group

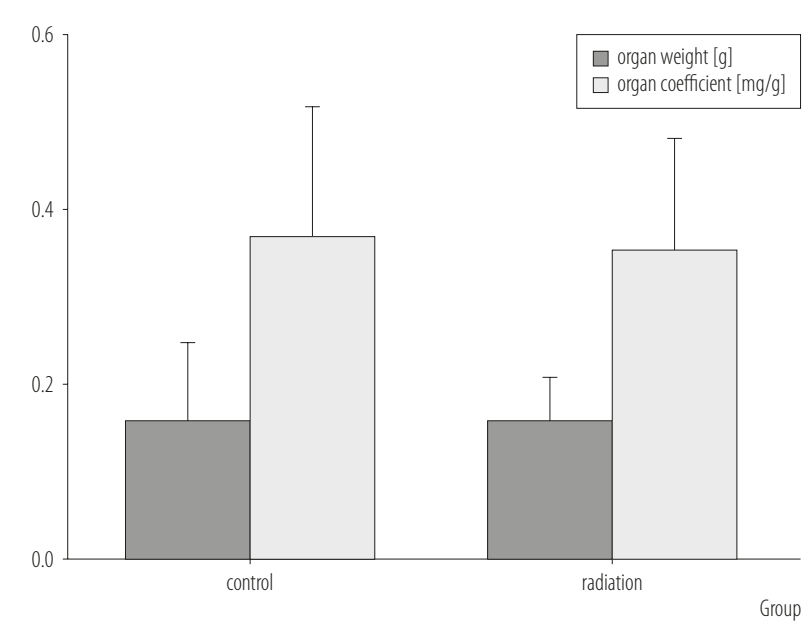

Fig. 4. Organ weight and organ coefficient of the spleen in mice

a model after sub-chronic occupational exposure. Histological evaluation of spleen from Kunming mice (Figure 5) revealed no abnormalities. Mononuclear cells were properly distributed in spleen and no difference was noticed in spleens from the occupational ELF-EMFs and the sham exposure treated animals.

\section{Effects of cytokine-specific messenger RNA (mRNA) in splenic tissues}

Mice were subchronically exposed to occupational levels of ELF-EMFs for 60 days. Splenic cytokine mRNAs were analyzed by the use of the reverse transcription real-time PCR. As shown in Figure 6, in the spleen tissues of the mice exposed to $50 \mathrm{~Hz}$ MFs the synthesized levels of IFN- $\gamma$, T-bet, IL-4, GATA-3, and IL-2 mRNAs were not statistically different from the same tissues taken from the sham exposed mice. Each run included 10 mice.

\section{Effects of cytokine-specific mRNA in primary splenic cells}

Mouse primary splenic cells were exposed to $50 \mathrm{~Hz}$ MFs for $6 \mathrm{~h}$ during culture. Experimental results for the effects of exposure to MFs at $0 \mu \mathrm{T}, 250 \mu \mathrm{T}, 500 \mu \mathrm{T}$, and $1 \mathrm{mT}$ in $50 \mathrm{~Hz}$ on the production of the 3 cytokines and 2 relative transcription factors are presented in Figure 7. The levels 

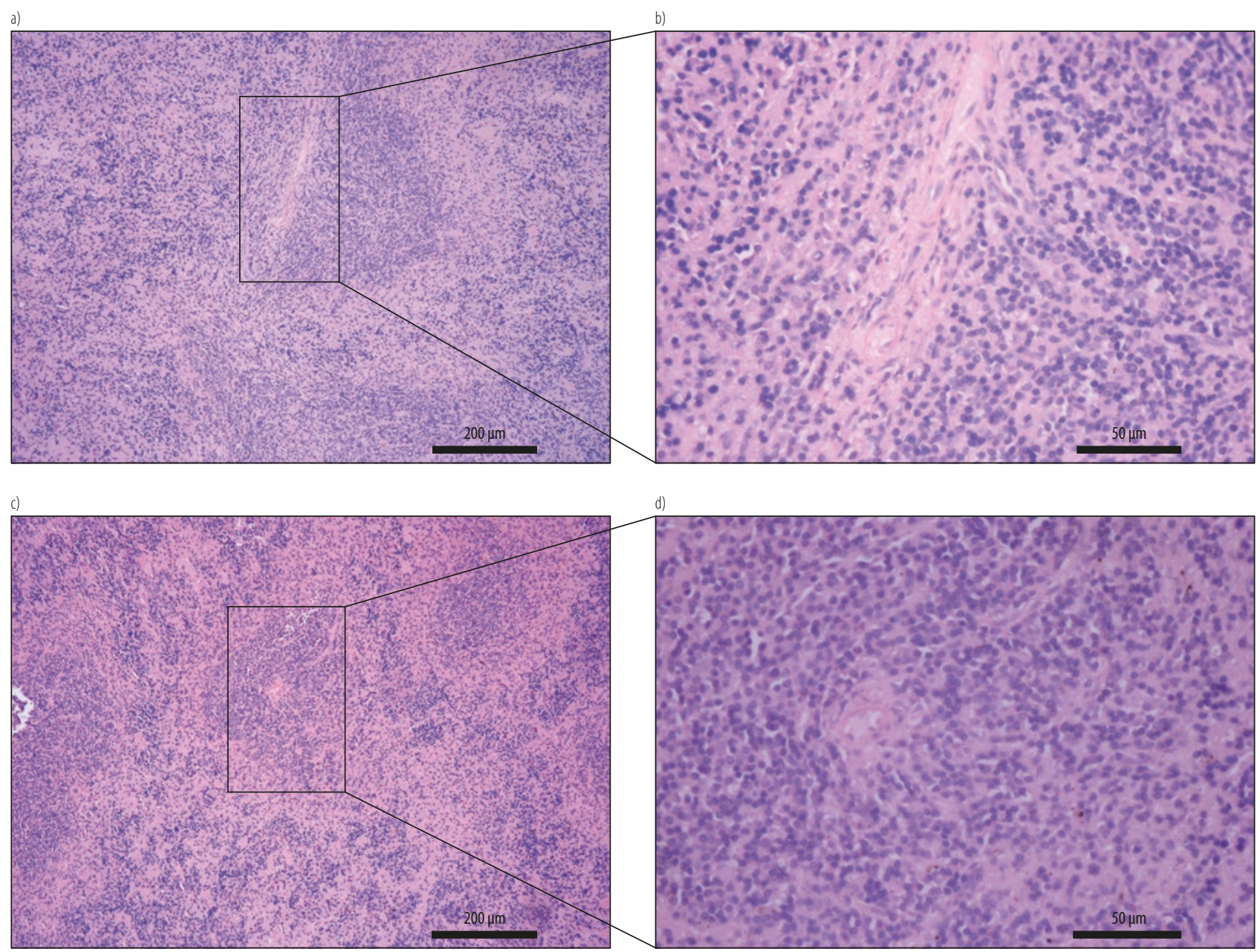

Fig. 5. Histological profile of spleens of Kunming mice after exposure to $50 \mathrm{~Hz}$ magnetic field (MF) the control group: a) magnification $100 \times$, b) $400 \times$, and the radiation group: c) $100 \times$, d) $400 \times$

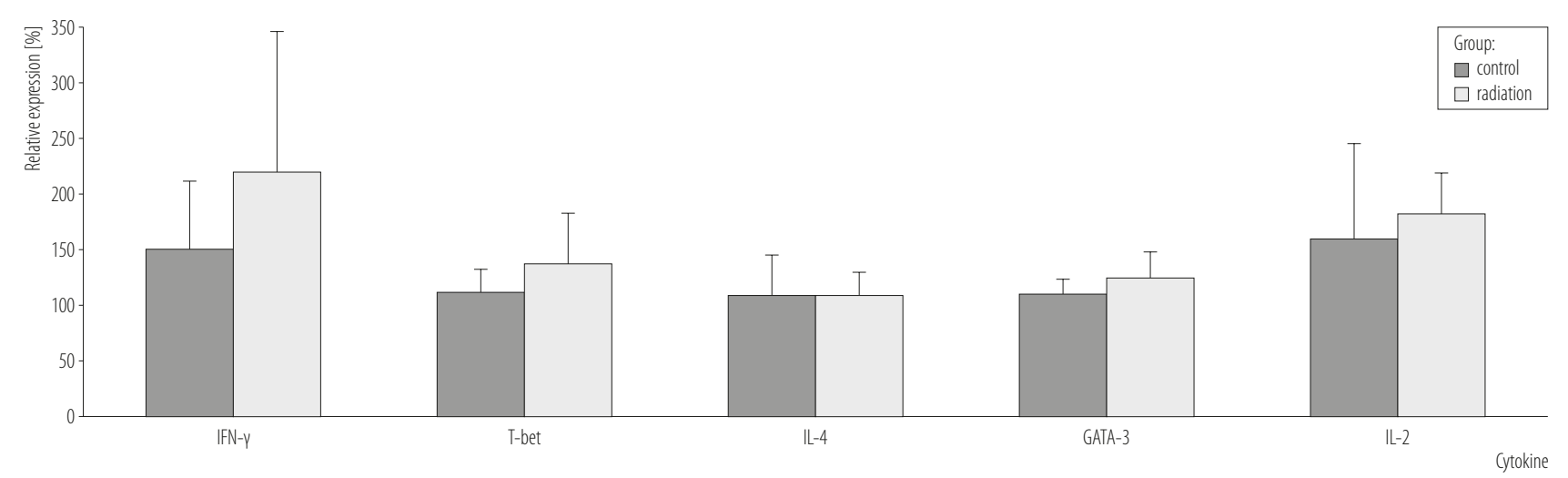

Abbreviations as in Figure 1.

Fig. 6. Cytokine messenger ribonucleic acids (mRNAs) of spleen tissues analyzed by the real-time quantitative reverse transcription polymerase chain reaction (RT-qPCR) 

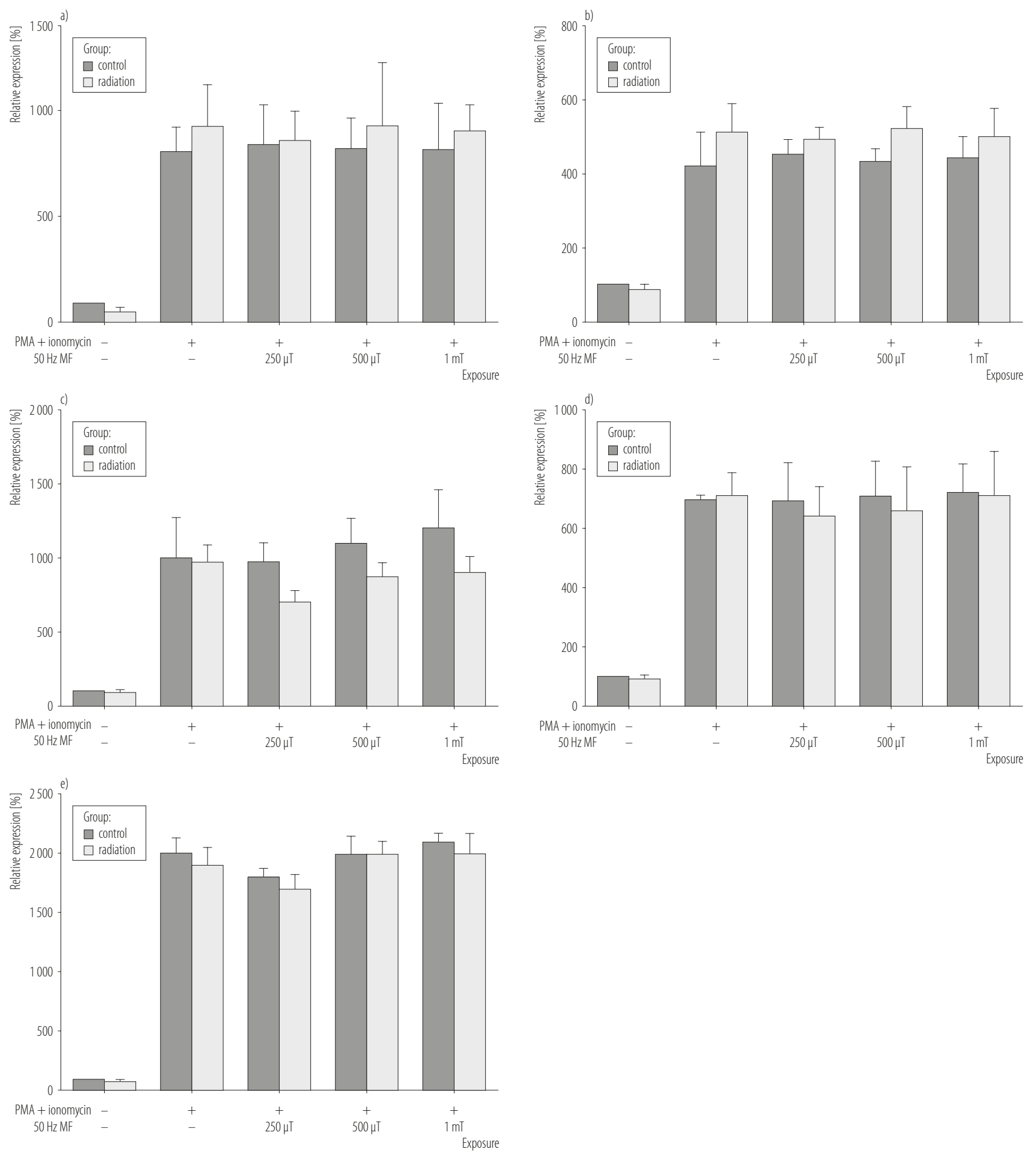

"+" - exposed; "-" - non-exposed.

Other abbreviations as in Figure 1 and 5.

Fig. 7. Cytokine messenger ribonucleic acids (mRNAs) of prime splenic cells analyzed by the real-time quantitative reverse transcription polymerase chain reaction (RT-qPCR): a) IFN- $\gamma$, b) T-bet, c) IL-4, d) GATA-3, e) IL-2 
of IFN- $\gamma$, T-bet, IL-4, GATA-3, and IL-2 mRNAs activation by PMA and ionomycin did not change significantly in a dose-dependent manner following MFs exposure. Ten mice were used for each run.

\section{Effects of $50 \mathrm{~Hz}$ MFs on T cells activation}

To investigate the role of $50 \mathrm{~Hz}$ MFs on primary splenic $\mathrm{T}$ cell activation, we used the primary splenic $\mathrm{T}$ cells freshly isolated from 10 healthy Kunming mice as model systems. Primary splenic T cells were stimulated with ionomycin, a calcium $\left(\mathrm{Ca}^{2+}\right)$ stimulus, in combination with PMA, which mimics antigen signals for $\mathrm{T}$ cell activation, in the absence or presence of electromagnetic fields of different intensity. The effect of $50 \mathrm{~Hz}$ MFs on the status of T cell activation was evaluated by the cell surface expression levels of CD69, an early activation marker of $\mathrm{T}$ cells. The experiment showed that PMA/ ionomycin stimulation resulted in an increase in CD69 expression in prime splenic $\mathrm{T}$ cell. However, in the presence of different intensity of electromagnetic fields, CD69 expression levels were not changed (Figure 8 and 9).

\section{DISCUSSION}

During the last 30 years, public concern about the possible harmful effects of magnetic fields generated by power lines and domestic appliances has been continuously increasing. With the wide use of $50 \mathrm{~Hz}$ MFs in modern society, it is important to investigate the possible deleterious health effects due to occupational and residential exposure [22-25]. The guideline for occupational exposure to power frequency magnetic fields at $50 \mathrm{~Hz}$ is $0.5 \mathrm{mT}$ for the International Committee on Non-Ionizing Radiation Protection (ICNIRP) and for the International Radiation Protection Association (IRPA). The World Health Organization's International Agency for Research on Cancer also used $500 \mathrm{mT}$ as a guideline. In America, the guideline for occupational exposure is $1 \mathrm{mT}$ for the American Conference of Governmental Industrial Hygienists $\left(\mathrm{ACGIH}^{\circledR}\right)$. Thus, in our study, mice were subchronically exposed to $500 \mu \mathrm{T}$ at $50 \mathrm{~Hz}$ MFs for $8 \mathrm{~h}$ daily to simulate occupational exposure.

Body weight is an important index, which can reflect toxic effects on an animal's health status. There has been a study, in which adult male and female Swiss mice were exposed to a $50 \mathrm{~Hz}$ sinusoidal magnetic field at $25 \mu \mathrm{T}$ for 90 days. The authors have found that exposure of male and female mice to the $50 \mathrm{~Hz}$ magnetic field had no significant effect on body weight [26]. There has been another study [27] where adult male Sprague-Dawley rats were exposed to a $50 \mathrm{~Hz}$ sinusoidal magnetic field at approximately $25 \mathrm{mT}$ for 18 consecutive weeks. There were no significant effects on the absolute body weight. However, weight of seminal vesicles and preputial glands was significantly reduced in the exposed male rats [27].

In our study, body weight of the mice exposed to occupational ELF-EMFs significantly decreased on day 20 and day 30, suggesting that under such experimental conditions ELF-EMFs could affect mouse body weight. In other research, the reason of body weight maintenance might have been caused by a low intensity of EMFs.

Spleen is the largest lymphoid organ and plays an important role in modulating immune function. The visceral index can often better reflect the integrated toxicity of toxic factors to the organ. Arafa et al. [28] have investigated bioeffects of a repeated daily exposure to $50 \mathrm{~Hz}$ high-intensity (20 mT, $200 \mathrm{G})$ MFs for $30 \mathrm{~min} 3$ times per week for 2 weeks on some immune parameters in mice. Total body weight gain in mice decreased significantly, while the spleen/body weight ratio was unchanged. In our study, there were no significant differences in the splenic coefficient. There was no adverse effect on spleen histology profile with $500 \mu \mathrm{T} 50 \mathrm{~Hz}$ MFs subchronic occupational exposure. Thus, in contrast to adult mice, MFs might affect the volume of spleen in newborn animals following prenatal exposure to ELF-MFs.

Several types of cytokines mediate important immune responses, which affect immune cells and many kinds of cells 

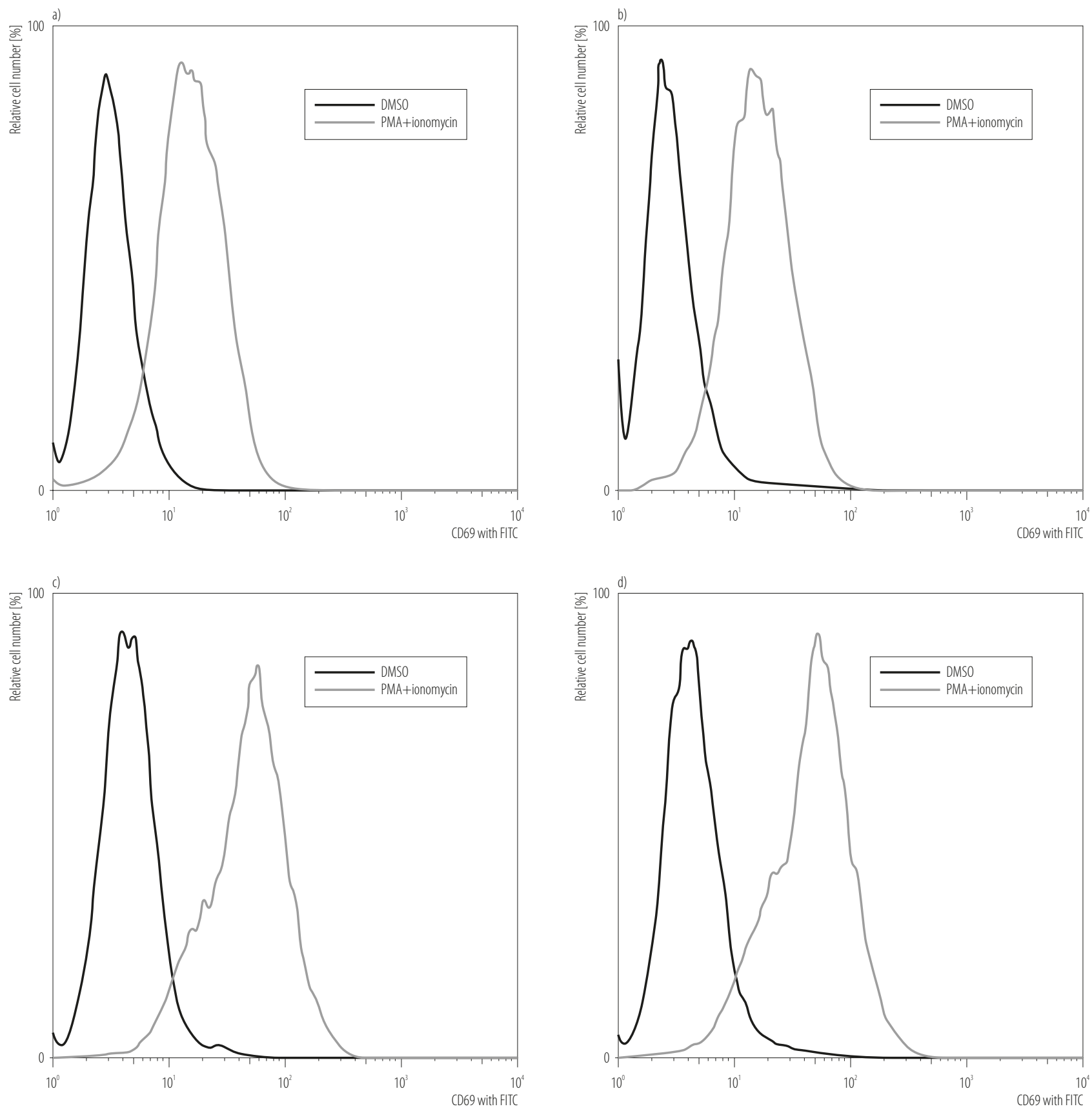

DMSO - dimethyl sulfoxide; PMA - para-Methoxyamphetamine; FITC - fluorescein isothiocyanate.

Fig. 8. Cluster of differentiation 69 (CD69) expression levels of prime splenic T cells analyzed by the flow cytometry: a) control group, b) $250 \mu \mathrm{T}$, c) $500 \mu \mathrm{T}$, d) $1 \mathrm{mT}$ exposed

outside the immune system. The cytokines IFN- $\gamma$ and IL-2 are produced by $\mathrm{T}$ helper 1 (Th1) cells that can activate macrophages to destroy intracellular microorganisms more efficiently. The cytokine IL-4 produced by Th2 cells can drive $\mathrm{B}$ cells to proliferate and produce antibodies such as immunoglobulin $\mathrm{G}$ ( $\operatorname{Ig} G)$. 


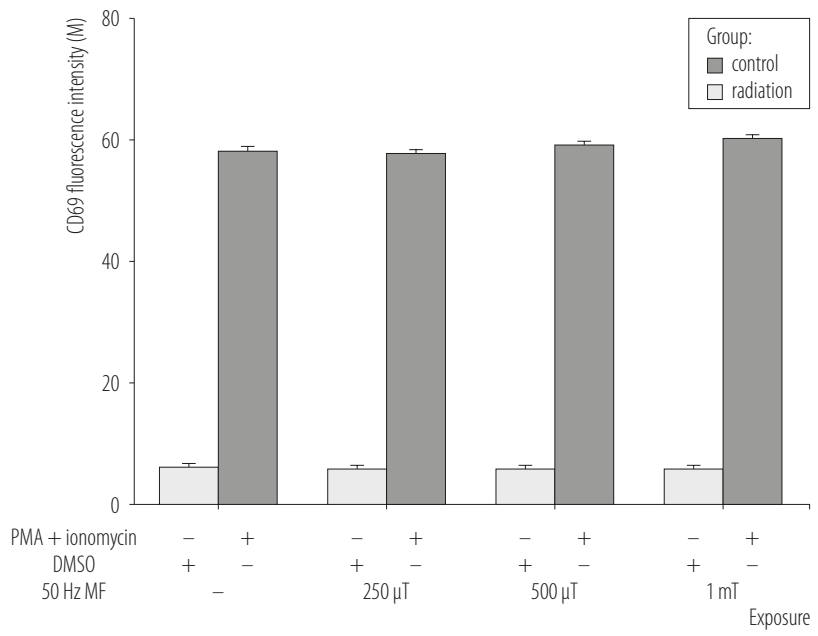

$\mathrm{M}$ - mean. Other abbreviations as in Figure 7 and 8.

Fig. 9. Mean fluorescence intensity of cluster of differentiation 69 (CD69) - no effects on prime splenic T cell activation with $50 \mathrm{~Hz}$ MFs

Jonai et al. [29] have reported decreases in the spontaneous production of IFN- $\gamma$ at $10000 \mu \mathrm{T}$ in human peripheral blood mononuclear cells (PBMCs) collected from only 1 healthy female volunteer. In Cossarizza et al.'s research, extremely low frequency pulsed electromagnetic fields could increase IL-2 utilization and IL-2 receptor expression in mitogen-stimulated human lymphocytes from old subjects [30]. However, the authors have also found that extremely low frequency pulsed electromagnetic fields increased cell proliferation in lymphocytes from young and aged subjects [31]. Moreover, they have certificated that exposure to low frequency pulsed electromagnetic fields increased mitogeninduced lymphocyte proliferation in Down's syndrome [32]. When Cossarizza et al. [15] have exposed human peripheral blood mononuclear cells to PEMFs, PEMFs increased both the spontaneous and the PHA- and TPA-induced production of IL-1 and IL-6. They have suggested that cells of the monocytic lineage, which are good producers of both IL-1 and IL-6, can be important cellular targets for PEMFs [15]. Taking into account that these cytokines are among the most pleiotropic ones, the data can help us understand the previous reported effects of PEMFs on the proliferation of human lymphocytes and the effects exerted by such fields on cartilage and bone cells, the physiological activity of which is highly dependent on IL-1 and IL-6 [15].

Ikeda et al. [17] have shown that $50 \mathrm{~Hz}$ and $60 \mathrm{~Hz}$, linearly, elliptically, and circularly polarized MFs of $500 \mathrm{mT}$ and linearly polarized MFs of $100 \mathrm{mT}, 20 \mathrm{mT}$, and $2 \mathrm{mT}$ root mean square (rms) did not affect in vitro human immunological functions such as cell produced cytokines (IFN- $\gamma$, TNF- $\alpha$, IL-2, and IL-10).

In our study, synthesized levels of IFN- $\gamma$, IL-2, IL-4 mRNAs in mouse spleen tissues exposed to $50 \mathrm{~Hz}$ MFs were not statistically different from the same tissues taken from the sham exposed mice. The 2 transcription factors, T-bet and GATA-3, associated with Th1 and Th2 modulation, respectively, were not activated in the mice following exposure to $50 \mathrm{~Hz}$ MFs. Moreover, T cell activation plays a critical role in regulation of both normal and pathogenic immune responses. Thus, our in vitro study was carried out to examine the effects of $50 \mathrm{~Hz}$ MFs on the expression of inflammatory factor genes and CD69 in mouse prime splenic lymphocytes activation by PMA and ionomycin. However, $50 \mathrm{~Hz}$ MF did not change the level of IFN- $\gamma$, IL-2 and IL-4 mRNAs, and the expression of CD69. This inconsistency may be due to the differences in the type of magnetic fields, the intensities used or the different cell types.

\section{CONCLUSIONS}

Under our experimental conditions, body weight of the mice exposed to occupational ELF-EMFs was significantly decreased on day 20 and day 30. The results presented here suggest that subchronic exposure to $500 \mu \mathrm{T} 50 \mathrm{~Hz}$ MFs in Kunming mice had no effects on splenic weight, splenic coefficient, splenic histology profile and cytokine production in the spleen. Moreover, our in vitro study showed that $50 \mathrm{~Hz}$ MFs of $250 \mu \mathrm{T}, 500 \mu \mathrm{T}$, and $1 \mathrm{mT}$ did not affect expression of inflammatory factor genes and CD69 in mouse prime splenic lymphocytes. 


\section{ACKNOWLEDGMENTS}

We are grateful to the International Science Editing, Ireland for editing the manuscript.

\section{REFERENCES}

1. Repacholi M. Concern that "EMF" magnetic fields from power lines cause cancer. Sci Total Environ. 2012;426:454-8, http://dx.doi.org/10.1016/j.scitotenv.2012.03.030.

2. Bernard N, Alberdi AJ, Tanguy ML, Brugere H, Helissey P, Hubert $\mathrm{C}$, et al. Assessing the potential leukemogenic effects of $50 \mathrm{~Hz}$ magnetic fields and their harmonics using an animal leukemia model. J Radiat Res. 2008;49(6):565-77.

3. Delpizzo V. An evaluation of the existing evidence on the carcinogenic potential of extremely low frequency magnetic fields. Australas Phys Eng Sci Med. 1989;12(2):55-68.

4. Yokus B, Akdag MZ, Dasdag S, Cakir DU, Kizil M. Extremely low frequency magnetic fields cause oxidative DNA damage in rats. Int J Radiat Biol. 2008;84(10):789-95, http:// dx.doi.org/10.1080/09553000802348203.

5. Akdag MZ, Dasdag S, Uzunlar AK, Ulukaya E, Oral AY, Celik N, et al. Can safe and long-term exposure to extremely low frequency $(50 \mathrm{~Hz})$ magnetic fields affect apoptosis, reproduction, and oxidative stress? Int J Radiat Biol. 2013;89(12): 1053-60, http://dx.doi.org/10.3109/09553002.2013.817705.

6. Khaki A, Imani SAM, Golzar FS. Effects of rosmarinic acid on male sex hormones (testosterone-FSH-LH) and testis tissue apoptosis after exposure to electromagnetic field (EMF) in rats. Afr J Pharm Pharmacol. 2012;6(4):248-52, http:// dx.doi.org/10.5897/AJPP11.701.

7. Murbach M, Christopoulou M, Crespo-Valero P, Achermann P, Kuster N. Exposure system to study hypotheses of ELF and RF electromagnetic field interactions of mobile phones with the central nervous system. Bioelectromagnetics. 2012;33(6):527-33, http://dx.doi.org/10.1002/bem.21710.

8. Akdag MZ, Dasdag S, Ketani MA, Sagsoz H. Effect of extremely low frequency magnetic fields in safety standards on structure of acidophilic and basophilic cells in anteriorpituitary gland of rats: An experimental study. J Int Dent Med Res. 2009;2(2):61-6.
9. Akdag MZ, Dasdag S, Ulukaya E, Uzunlar AK, Kurt MA, Taskin A. Effects of extremely low-frequency magnetic field on caspase activities and oxidative stress values in rat brain. Biol Trace Elem Res. 2010;138(1-3):238-49, http://dx.doi. org/10.1007/s12011-010-8615-3.

10. Akdag MZ, Dasdag S, Cakir DU, Yokus B, Kizil G, Kizil M. Do 100- and 500- $\mu$ T ELF magnetic fields alter beta-amyloid protein, protein carbonyl and malondialdehyde in rat brains? Electromagn Biol Med. 2013;32(3):363-72, http://dx.doi.org/ 10.3109/15368378.2012.721848.

11. Del Seppia C, Mencacci R, Luschi P, Varanini M, Ghione S. Differential magnetic field effects on heart rate and nociception in anosmic pigeons. Bioelectromagnetics. 2012;33(4):309-19, http://dx.doi.org/10.1002/bem.20708.

12. Schuz J. Exposure to extremely low-frequency magnetic fields and the risk of childhood cancer: Update of the epidemiological evidence. Prog Biophys Mol Biol. 2011;107(3):33942, http://dx.doi.org/10.1016/j.pbiomolbio.2011.09.008.

13. Wünsch-Filho V, Pelissari DM, Barbieri FE, Sant'Anna L, de Oliveira CT, de Mata JF, et al. Exposure to magnetic fields and childhood acute lymphocytic leukemia in São Paulo, Brazil. Cancer Epidemiol. 2011;35(6):534-9, http:// dx.doi.org/10.1016/j.canep.2011.05.008.

14. Kheifets L, Bowman JD, Checkoway H, Feychting M, Harrington JM, Kavet R, et al. Future needs of occupational epidemiology of extremely low frequency electric and magnetic fields: Review and recommendations. Occup Environ Med. 2009;66(2):72-80, http://dx.doi.org/10.1136/ oem.2007.037994.

15. Cossarizza A, Angioni S, Petraglia F, Genazzani AR, Monti D, Capri M, et al. Exposure to low frequency pulsed electromagnetic fields increases interleukin-1 and interleukin-6 production by human peripheral blood mononuclear cells. Exp Cell Res. 1993;204(2):385-7, http://dx.doi.org/10.1016/ j.cyto.2010.12.016.

16. Gobba F, Bargellini A, Scaringi M, Bravo G, Borella P. Extremely low frequency-magnetic fields (ELF-EMF) occupational exposure and natural killer activity in peripheral 
blood lymphocytes. Sci Total Environ. 2009;407(3):1218-23, http://dx.doi.org/10.1016/j.scitotenv.2008.08.012.

17. Ikeda K, Shinmura Y, Mizoe H, Yoshizawa H, Yoshida A, Kanao S, et al. No effects of extremely low frequency magnetic fields found on cytotoxic activities and cytokine production of human peripheral blood mononuclear cells in vitro. Bioelectromagnetics. 2003;24(1):21-31, http://dx.doi. org/10.1002/bem.10062.

18. De Kleijn S, Bouwens M, Verburg-van Kemenade BM, Cuppen JJ, Ferwerda G, Hermans PW. Extremely low frequency electromagnetic field exposure does not modulate toll-like receptor signaling in human peripheral blood mononuclear cells. Cytokine. 2011;54(1):43-50, http://dx.doi.org/10.1016/ j.cyto.2010.12.016.

19. Bouwens M, de Kleijn S, Ferwerda G, Cuppen JJ, Savelkoul HF, Kemenade BM. Low-frequency electromagnetic fields do not alter responses of inflammatory genes and proteins in human monocytes and immune cell lines. Bioelectromagnetics. 2012;33(3):226-37, http://dx.doi.org/10.1002/ bem. 20695 .

20. Duan W, Liu C, Wu H, Chen C, Zhang T, Gao P, et al. Effects of exposure to extremely low frequency magnetic fields on spermatogenesis in adult rats. Bioelectromagnetics. 2013;35(1):58-69, http://dx.doi.org/10.1002/ bem.21816.

21. Ma Q, Deng P, Zhu G, Liu C, Zhang L, Zhou Z, et al. Extremely low-frequency electromagnetic fields affect transcript levels of neuronal differentiation-related genes in embryonic neural stem cells. PLoS One. 2014;9(3):e90041, http://dx.doi.org/10.1371/journal.pone.0090041.

22. Touitou Y, Djeridane Y, Lambrozo J, Camus F. Longterm (up to 20 years) effects of $50-\mathrm{Hz}$ magnetic field exposure on blood chemistry parameters in healthy men. Clin Biochem. 2012;45(6):425-8, http://dx.doi.org/10.1016/j.clinbiochem.2011.12.020.

23. Karpowicz J, Zradziński P, Gryz K. [Measures of occupational exposure to time-varying low frequency magnetic fields of non-uniform spatial distribution in the light of international guidelines and electrodynamic exposure effects in the human body]. Med Pr. 2012;63(3):317-28. Polish.

24. Comba P, Fazzo L. Health effects of magnetic fields generated from power lines: New clues for an old puzzle. Ann Ist Super Sanita. 2009;45(3):233-7.

25. Fazzo L, Tancioni V, Polichetti A, Iavarone I, Vanacore N, Papini P, et al. Morbidity experience in populations residentially exposed to $50 \mathrm{~Hz}$ magnetic fields: Methodology and preliminary findings of a cohort study. Int J Occup Environ Health. 2009;15(2):133-42.

26. Elbetieha A, Al-Akhras MA, Darmani H. Long-term exposure of male and female mice to $50 \mathrm{~Hz}$ magnetic field: Effects on fertility. Bioelectromagnetics. 2002;23(2):168-72, http://dx.doi.org/10.1002/bem.109.

27. Al-Akhras MA, Darmani H, Elbetieha A. Influence of $50 \mathrm{~Hz}$ magnetic field on sex hormones and other fertility parameters of adult male rats. Bioelectromagnetics. 2006;27(2):12731, http://dx.doi.org/10.1002/bem.20186.

28. Arafa HM, Abd-Allah AR, El-Mahdy MA, Ramadan LA, Hamada FM. Immunomodulatory effects of L-carnitine and q10 in mouse spleen exposed to low-frequency highintensity magnetic field. Toxicology. 2003;187(2-3):171-81, http://dx.doi.org/10.1016/S0300-483X(03)00050-7.

29. Jonai H, Villanueva MB, Yasuda A. Cytokine profile of human peripheral blood mononuclear cells exposed to $50 \mathrm{~Hz}$ EMF. Ind Health. 1996;34(4):359-68, http://dx.doi. org/10.2486/indhealth.34.359.

30. Cossarizza A, Monti D, Bersani F, Paganelli R, Montagnani G, Cadossi R, et al. Extremely low frequency pulsed electromagnetic fields increase interleukin-2 (IL-2) utilization and IL-2 receptor expression in mitogen-stimulated human lymphocytes from old subjects. FEBS Lett. 1989;248(1-2):141-4, http://dx.doi.org/10.1016/0014-57 93(89)80449-1.

31. Cossarizza A, Monti D, Bersani F, Cantini M, Cadossi R, Sacchi A, et al. Extremely low frequency pulsed electromagnetic fields increase cell proliferation in lymphocytes from young and aged subjects. Biochem Biophys Res 
Commun. 1989;160(2):692-8, http://dx.doi.org/10.1016/00 06-291X(89)92488-1.

32. Cossarizza A, Monti D, Bersani F, Scarfi MR, Zanotti M, Cadossi R, et al. Exposure to low-frequency pulsed electromagnetic fields increases mitogen-induced lymphocyte proliferation in Down's syndrome. Aging (Milano). 1991;3(3):241-6, http://dx.doi.org/10.1007/bf0 3324014.

This work is available in Open Access model and licensed under a Creative Commons Attribution-NonCommercial 3.0 Poland License - http://creativecommons.org/ licenses/by-nc/3.0/pl/deed.en. 